TABLE IV.-Investigation of Anaemia Below $80 \%$ Haemoglobin

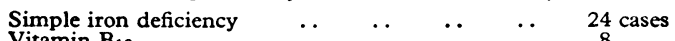
Vitamin $B_{12}$
$\Rightarrow$

\section{Discussion}

The absence of obstructive sequelae in these cases supports the view that when they occur after forms of gastrectomy in which a jejunal loop has been used for the anastomosis the loop is indeed the obstructive agent. It suggests also that the general adoption of the no-loop technique would remove the threat of the so-called postgastrectomy syndrome as a risk incurred by partial gastrectomy in the treatment of duodenal ulcer.

The small incidence of diarrhoea and the absence of recurrent ulceration compare favourably with both vagotomy and loop gastrectomy. Limitation of meals and vulnerability to anaemia can be contained by adequate measures. Nevertheless, they do constitute a real disadvantage. We think that they are both due to the rather extensive (three-quarters) resection of the stomach that has been carried out in this series. This has been done on the supposition that it was necessary to avoid stomal ulceration, but the results suggest that this may not be so. It is probable that the no-loop technique will permit the retentios of a greater proportion of the stomach with less disturbance of function afterwards.

\section{Summary}

The no-loop technique in partial gastrectomy for duodenal ulcer avoids the liability to postgastrectomy syndromes, reduces the risk of recurrent ulcer, and preserves nutrition by maintaining a measure of physiological digestion in the duodenum.

\section{REFERENCES}

Johnston, D., and Duthie, H. L. (1964). Gut, 5, 573.

Orr, I. (1964). Ann. roy. Coll. Surg. Engl., 34, 314.

Stammers, F. A. R. (1954). Brit. F. Surg., 42, 34.

- (1961). Ibid., 49, 28.

Tanner, N. C. (1954). Postgrad. med. F., 30, 448

Taylor, H. (1959). Brit. med. F., 1, 1133.

(1964). Proceedings of International Congress of Gastroenterology. vol. I, p. 218.

\title{
Renal Artery Stenosis with Hypertension and High Haematocrit
}

\author{
PETER HUDGSON,* M.B., M.R.A.C.P. ; JOHN M. S. PEARCE,*† M.D., M.R.C.P. \\ W. KEITH YEATES, $\ddagger$ M.D., M.S., F.R.C.S.
}

Brit. med. 9., 1967, 1, 18-21

In recent years experimental and clinical evidence has accumulated implying that renal erythropoietin is of importance in red-cell production under physiological and pathological conditions. It has been suggested that erythropoietin deficiency may be important in the anaemia of chronic destructive renal disease. Conversely, excessive elaboration of erythropoietin may be responsible for the polycythaemia sometimes seen in carcinoma of the kidney and other renal diseases, since high plasma levels of erythropoietin are occasionally found in the latter group of patients (Jacobson et al., 1957 ; Gurney et al., 1961 ; Penington, 1962 ; Brandt et al., 1963). Abnormally high tissue concentrations of erythropoietin have also been demonstrated in discrete pathological lesions such as tumours or cysts in the affected kidneys (Gurney et al., 1961 ; Penington, 1962). Blanshard and Smith (1964) have demonstrated increased tissue erythropoietin concentrations in distant metastases from a renal carcinoma. The role of renal erythropoietin in experimental polycythaemia is reviewed by Osnes (1959) and Penington (1962).

Of the renal lesions associated with polycythaemia the best known are carcinomata and simple cysts of the kidney (Conley et al., 1957 ; Damon et al., 1958; Jones et al., 1960). It is clear, however, that renal adenomata, polycystic kidneys, hydronephrosis, and even uterine fibroids may on occasion be accompanied by polycythaemia (Gardner and Freymann, 1958; Lawrence and Donald, 1959 ; Brandt et al., 1963 ; Smith and Riches, 1963). There has been only one previously reported association between renal artery stenosis and renal poly-

- Department of Neurology, Regional Neurological Centre, Newcastle General Hospital, Newcastle upon Tyne.

tPresent address: Department of Neurology, Massachusetts General Hospital, Boston. U.S.A.

$\ddagger$ Department of Urology, Newcastle General Hospital, Newcastle upon Tyne cythaemia in the human (Luke et al., 1965). For this reason we record the occurrence of an uncommon type of renal artery stenosis accompanied by renal hypertension and polycythaemia, which we believe to be the second case in the English literature.

\section{Case Report}

The patient, a 45-year-old man, was admitted to the Regional Neurological Centre on 13 March 1964. He gave a history of several episodes of vertigo and ataxia with staggering to the left, which had begun in 1957. He noticed that during these attacks objects appeared to move from side to side. These attacks lasted about one week and recurred at approximately yearly intervals until 1960, after which time he remained symptom-free for three years. He had two further attacks in June and November 1963, each of which lasted three weeks and was accompanied by weakness, stiffness, and sensory disturbance on the left side of the body. The latter episode was also attended by nausea and vomiting, and left him with residual weakness and stiffness in the left leg. He had no family history of essential hypertension or of occlusive vascular disease.

On examination he appeared to be in good health, but his blood: pressure was never less than 230/140 even after rest in bed. The cardiovascular system was otherwise normal. Examination of the abdomen revealed a loud blowing systolic murmur in the transpyloric plane to the left of the midline and over the left renal angle at the back. The ocular fundi showed marked vascular narrowing with arteriovenous nipping, and a single large "cotton-wool" exudate medial to the disc in the right fundus. Examination of the central nervous system showed weakness of pyramidal type with an increase in tone in the left leg. The deep tendon reflexes in the left leg were hyperactive but both plantar reflexes were flexor. There was mild cerebellar ataxia in both the upper and lower limbs on the left side. No other abnormal physical signs were found. 


\section{Special Investigations}

Central Nervous System.- $X$-ray pictures of skull (with special views of the internal auditory meatus) and cervical spine normal. Lumbar puncture showed clear colourless cerebrospinal fluid at normal pressure. Cerebrospinal fluid: total protein $31 \mathrm{mg} . / 100$ ml. ; gammaglobulin $3 \%$ of total protein; Lange curve normal ; W.R. negative; no cells seen on microscopy. Lumbar air encephalogram was normal ; in particular there was no evidence of a spaceoccupying lesion in the posterior fossa.

Renovascular. - X-ray picture of chest normal. Electrocardiogram: left ventricular hypertrophy and strain pattern. Urine microscopy and culture: no red cells and less than one pus cell per high-power field; a "colony count" indicated that the bacterial contamination rate was less than 10,000 organisms $/ \mathrm{ml}$. of urine. Blood urea $25 \mathrm{mg} . / 100 \mathrm{ml}$. Electrolytes: sodium $139 \mathrm{mEq} / \mathrm{l}$, potassium $5.2 \mathrm{mEq} / 1$., chloride $96 \mathrm{mEq} / 1$., carbon-dioxide-combining power $30.5 \mathrm{mEq} / 1$. Vanil-mandelic acid excretion $2.1 \mathrm{mg}$. in 24 hours. Intravenous pyelogram (Fig. 1): the left kidney was slightly smaller than the right, and the dye concentration in the 15 -minute film was much greater on the left side than on the right ; the pelvicaliceal system on both sides appeared to be normal. Aortogram (Fig. 2) (Seldinger catheter via the right femoral artery): there was a tight stenosis of the left renal artery about $1 \mathrm{~cm}$. from its origin; the renal artery distal to the stenosis showed the "string of sausages" appearance described in stenosis due to fibromuscular hyperplasia of the vessel wall.

Haematological.-Haemoglobin 18.2 g./100 ml. (13 March), 20 g. (17 March), 18.2 g. (6 May). Packed cell volume $61^{\%}$ (13 March), 60\% (17 March), 54\% (6 May). White-cell count $6,600 / \mathrm{cu}$. mm. Blood film normal. E.S.R. $1 \mathrm{~mm}$. in 1 hour. Platelet count $128,000 / \mathrm{cu}$. mm. Red-cell mass $\left({ }^{51} \mathrm{Cr}\right.$-tagged red-cell method): preoperative $32.7 \mathrm{ml} . / \mathrm{kg}$. body weight; postoperative

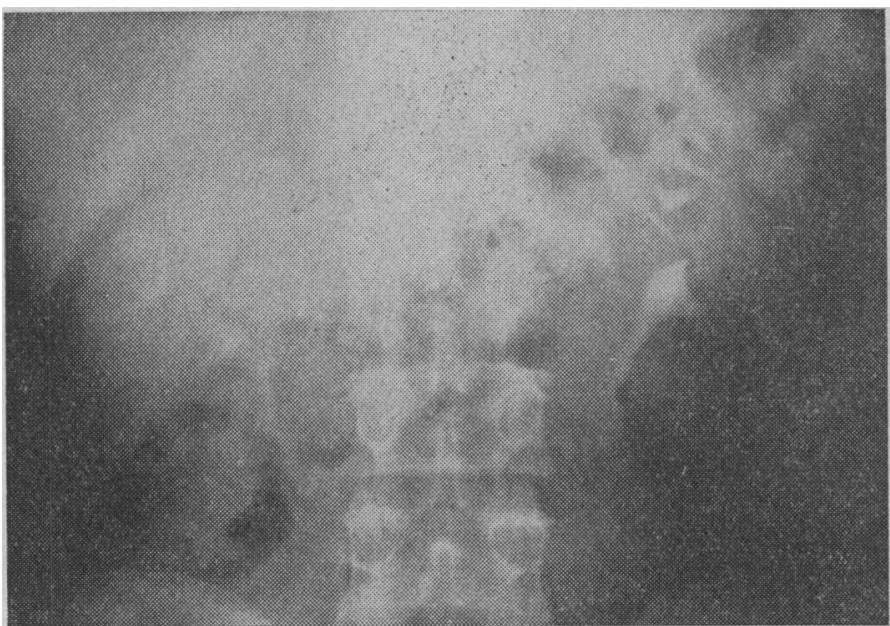

FIG. 1.-Inuravenous pyelogram showing increased dye concentration in the smaller affected left kidney.

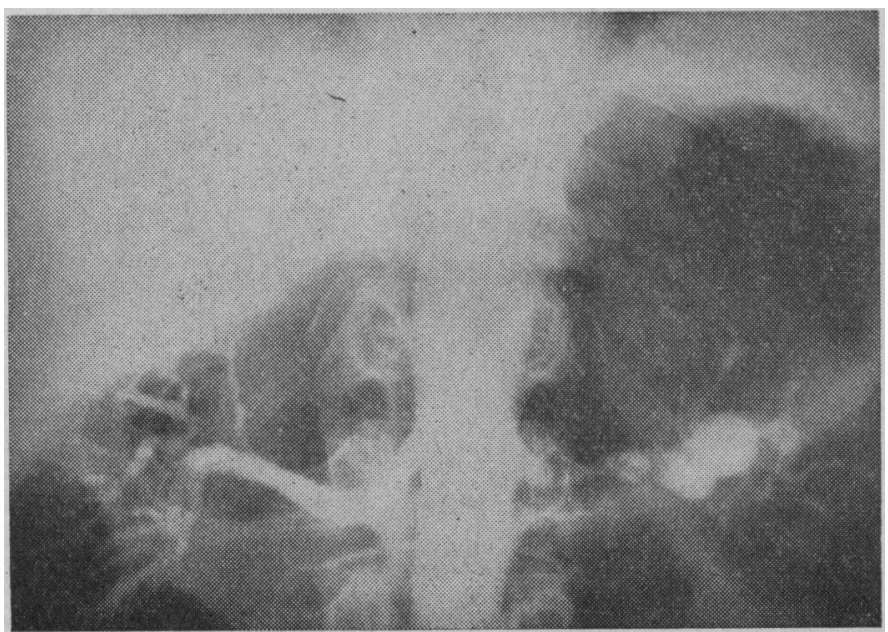

FIG. 2.-Aortogram showing "suring of sausages" appearance of left renal artery.
(March 1966) $26 \mathrm{ml} . / \mathrm{kg}$. body weight. Plasma volume (with same method as above): preoperative $28 \mathrm{ml} . / \mathrm{kg}$. body weight. Plasma erythropoietic activity (using iron uptake studies in polycythaemic rats) within normal range. Arterial oxygen saturation (Brinkman method) $97 \%$. Arterial carbon dioxide tension $41 \mathrm{~mm}$. $\mathrm{Hg}$

\section{Subsequent Management}

It was felt that the patient had been suffering from attacks of vertebrobasilar insufficiency associated with hypertension and polycythaemia, the former almost certainly being due to a stenosis of the left renal artery. Control of his hypertension with methyldopa and chlorothiazide was attempted but was unsuccessful. It was therefore decided that further investigation should be carried out with a view to surgical treatment of the renal artery stenosis. Cystoscopy with retrograde pyelography and differential renal-function tests were carried out on 7 May. The differential renal-function tests (see Table) supported the diagnosis of left-sided renal ischaemia. The retrograde pyelograms were normal in every respect. Percutaneous biopsy of the right kidney, carried out to exclude the presence of severe hypertensive damage, showed early hypertensive changes only (Fig. 3). It was felt that the angiographic

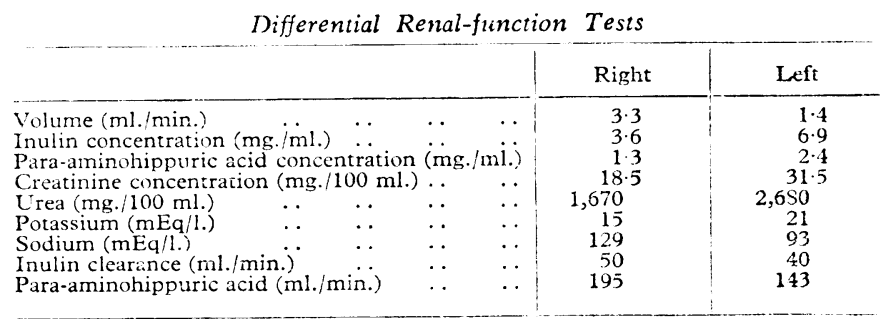

appearance of the left renal artery ruled out the possibility of successful prosthetic surgery, and this view was confirmed when the left kidney was explored by one of us (W. K. Y.) on 26 May. Exposure was achieved through a loin incision, excising the anterior half of the eleventh rib. The renal artery was doubly ligated with silk $1 \mathrm{~cm}$. from its origin and proximal to three thin-walled aneurysms. The largest of these measured $0.6 \mathrm{~cm}$. in diameter. The kidney was then removed. L oss of blood during the operation was minimal and the patient required only 1 pint $(570 \mathrm{ml}$.) of whole blood. This was transfused slowly throughout the procedure, no other intravenous fluids being given. After induction of the anaesthetic the blood pressure varied between $180 / 80$ and $160 / 80$, no significant change being recorded when the renal vessels were ligated. The blood pressure remained almost constantly at $170 / 110$ during the three days immediately after operation.

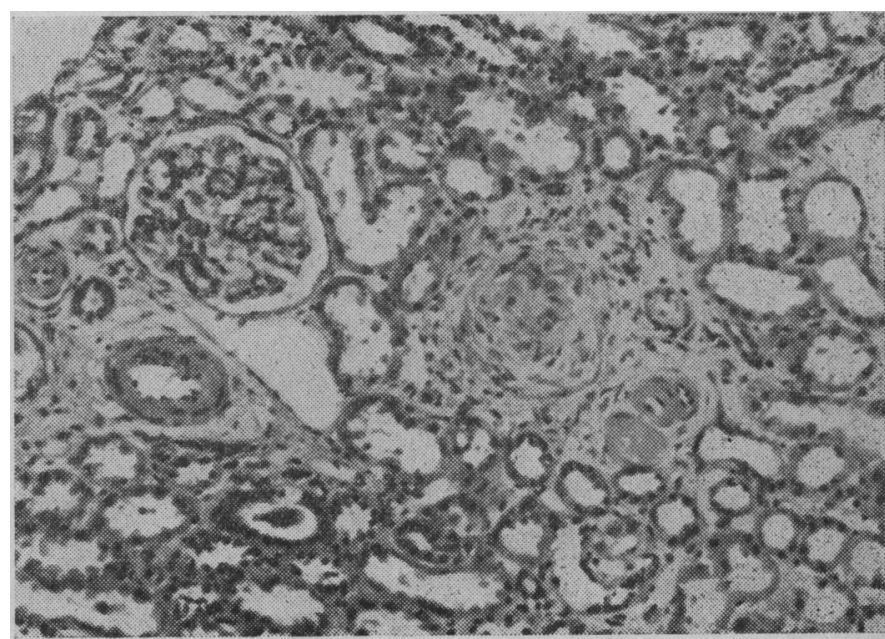

FIG. 3.-Biopsy of right kidney, showing early changes of hypertension. 
Subsequently the blood pressure was easily controlled between $140 / 90$ and $150 / 100$ with methyldopa $250 \mathrm{mg}$. four times daily, chlorothiazide $1 \mathrm{~g}$. daily, and potassium replacements. It conthued to fall steadily during the follow-up period of 18 months, and has remained normal for nine months. At the time of writing he was taking methyldopa $250 \mathrm{mg}$. daily only, and had so further episodes of brain-stem ischaemia. Regular blood sxaminations since his discharge from hospital have shown that his haemoglobin has fallen to a mean of $17 \mathrm{~g} . / 100 \mathrm{ml}$. , and his baematocrit to a mean of $52 \%$. The total white-cell count, differential count, and blood film have remained normal. A repeat red-cell-mass study recorded $26 \mathrm{ml} . / \mathrm{kg}$. body weight.

\section{Pathology}

Fig. 4 shows the removed left kidney, with the adjacent aneurysms on the renal artery, which are to be seen opened in Fig. 5. The aneurysms are presumably responsible for the "string of sausages" uppearance previously described. The histological appearance of the wall of the renal artery is shown in Fig. 6, which demonstrates considerable hypertrophy of the media with only a small atheromatous plaque overlying it. None of the other changes found in therosclerosis are present. These changes are typical of those reported in fibromuscular hyperplasia of the renal artery, and correlate well with the naked-eye appearances (Fig. 5). Microycopically the nephrectomy specimen shows very slight thickening of Bowman's capsule, hyalinization of the wall of a glomerular arteriole, and early tubular atrophy (Fig. 7). These changes are much less pronounced than those in the biopsy from the right kidney, preiumably because of the protective effect of the stenosis.

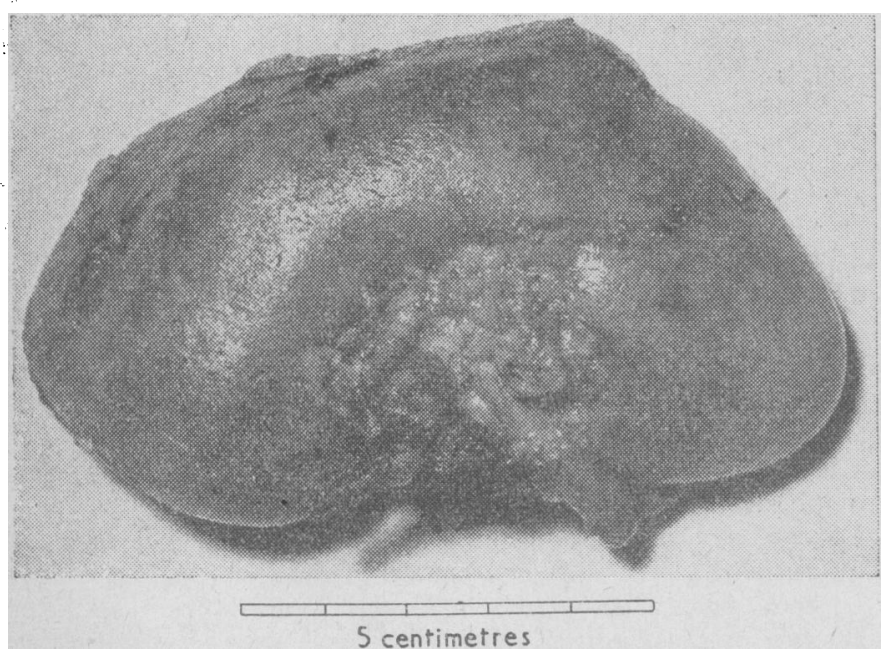

k1G. 4.-Laft kidney remuved at nephrectomy. Note aneurysmal dilataion of left rena! artery.

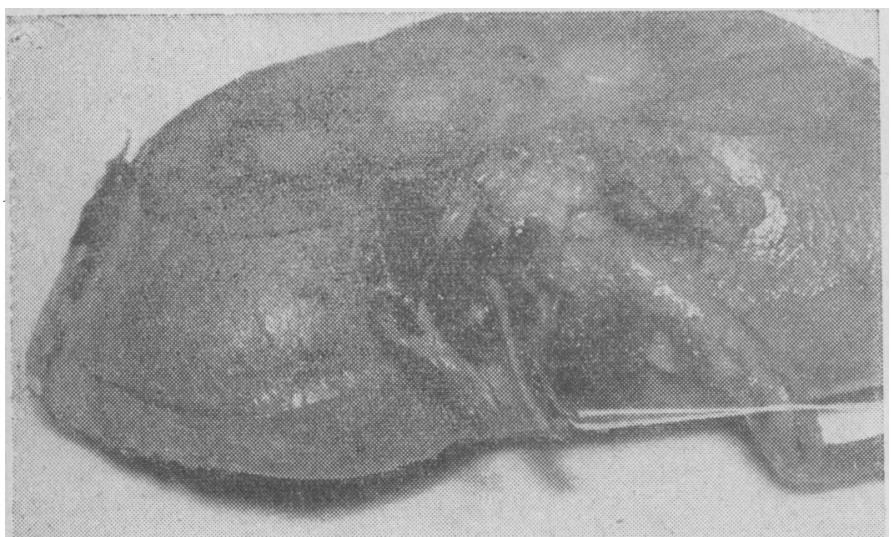
Fig. 5.-Left kidney and left renal artery, showing aneurysms of artery
as in Fig. 4 .

\section{Discussion}

In this patient renal artery stenosis was suggested by a renal bruit, a characteristic excretory pyelogram, differential renal excretion rates, and a renal aortogram. Proof of the stenosia was obtained when the kidney was removed. That the stenosis demonstrated was responsible for the patient's hypertension is indicated by the early age of onset, the absence of a family history of vascular disease, and the dramatic reversal of the hypertension by nephrectomy.

A haemoglobin value of 20 g. $/ 100 \mathrm{ml}$., a P.C.V. of $60 \%$, and an E.S.R. of $1 \mathrm{~mm}$. per hour strongly suggest the presence of polycythaemia. The normal white-cell and platelet count: and the absence of splenomegaly excluded polycythaemia rubra vera. Normal respiratory function and blood-gas analysis excluded chronic respiratory failure as a possible cause of erythrocytosis. In the presence of clearly demonstrated renal disease, and in view of the known association of renal lesions with polycythaemia, we concluded that a causal relationship was probably present in this patient.

$A$ curious and unexplained feature was the normal value obtained for the plasma volume and the red-cell mass, which was at the upper limit of normal before operation. Notwithstanding this, a significant reduction in the red-cell mass $(6.7 \mathrm{ml} . / \mathrm{kg}$. body weight) has occurred since nephrectomy. A normal red-cell mass is also known in "relative polycythaemia," but is due to extracellular dehydration, and is

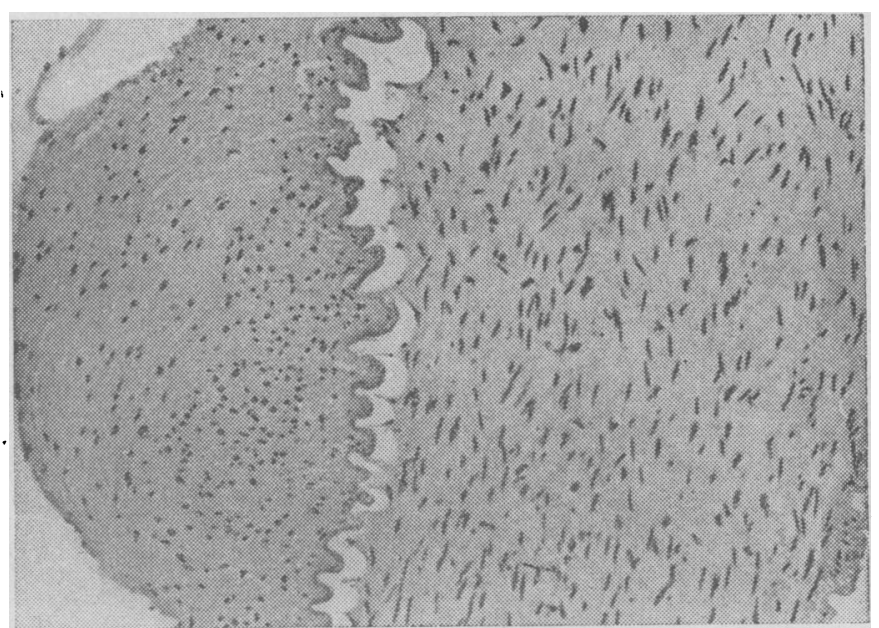

Fig. 6.-Histological section of renal artery. Gross hyperplasia of tunics media is seen, and the vessel shows minimal atheroma, the intima and internal elastic lamina being preserved.

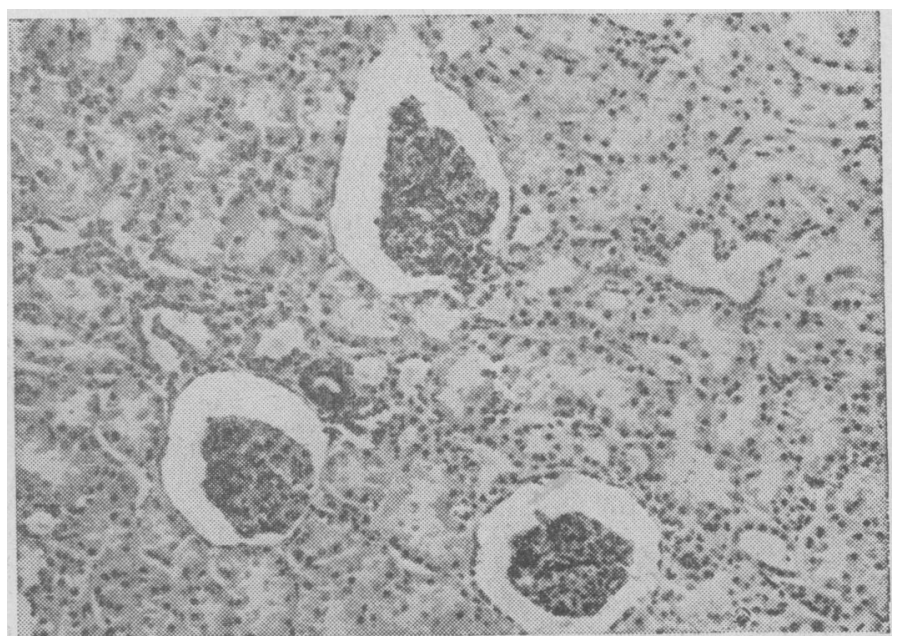

FIg. 7.-Histology of left kidney. Early tubular atrophy and some enlargement of Bowman's capsule are shown; arteriolar degeneration is minimal. 
therefore invariably accompanied by a low plasma volume; in the above case the plasma volume was normal. Despite these difficulties in allocation to a clearly defined group the results clearly indicate that the haematocrit values were repeatedly outside the normal range ; this is the most important practical criterion in the diagnosis of polycythaemia (De Gruchy, 1964). However, it is of interest that C. J. Hayter (personal communication, 1965) has found that many patients who have high haemoglobin and haematocrit values in routine tests are subsequently shown to have normal red-cell masses and plasma volumes. He suggests that the high haemoglobin and haematocrit levels may have an artifactual basis associated with the use of a tourniquet during venepuncture. It is possible that this may be the explanation of the high levels obtained so consistently in the above case.

The mechanisms of production of polycythaemia in renal disease are still incompletely understood. The high levels of erythropoietin found in renal tissue by Penington (1962) and by Blanshard and Smith (1964) are clearly important. However, the fact that erythropoiesis is not always stimulated by injections of erythropoietin in a patient suffering from chronic renal failure and anaemia (Van Dyke et al., 1963) suggests that stores of extrarenal erythropoietin and the responsiveness of the bone marrow are factors of importance in red-cell formation. Red-cell production continues in patients after total nephrectomy (Nathan et al., 1963), which suggests that renal erythropoietin may function largely as a reserve force in erythropoiesis, but may be relatively insignificant in normal circumstances.

It has been suggested that renal erythropoietin is secreted by the tubules in the presence of expanding renal lesions-for example, cysts and tumours-and this is explained by a postulated mechanism of reduced perfusion with blood, a result of raised intrarenal tension. If a reduced blood supply to the nephrons is the critical factor in the release of this hormone, then it is easy to understand the polycythaemia of renal artery stenosis (Luke et al., 1965). However, if this is the mechanism of this condition it is remarkable that more examples of the association of renal artery stenosis and polycythaemia have not been recorded. For this reason it is likely that other undiscovered mechanisms are operative.

The only reported example of this association is that of Luke et al. (1965), in which a 54-year-old man was relieved of malignant hypertension and polycythaemia by nephrectomy. In our patient the hypertension has been reversed, and the red-cell mass has fallen from 32.7 to $26 \mathrm{ml} . / \mathrm{kg}$. body weight. Luke and his colleagues suggest that "polycythaemia hypertonica "-Gaisböck's (1905) syndrome-may include patients with renal polycythaemia and hypertension. This syndrome includes polycythaemia without splenomegaly, hypertension, cyanosis, and renal disease. It is well recognized that hypertension complicates $50 \%$ of patients suffering from polycythaemia vera, and that splenomegaly is absent in one-third in such cases (De Gruchy, 1964). For this reason it is probable that most examples of Gaisböck's syndrome are in reality cases of polycythaemia vera, but it is possible that a renal cause underlies this syndrome in some cases.

Of the many pathological processes that are responsible for renal artery stenosis atherosclerosis is the most common. The radiological and pathological studies in the present case (Figs. 2,
4,5 , and 6) clearly demonstrate that atherosclerosis is not the primary lesion. The "sausage string" or "row of beads" appearance is characteristic of fibromuscular hyperplasia of the renal artery. The gross hyperplastic changes seen histologically confirm this diagnosis and closely resemble the findings of Van Wyk (1964). This uncommon condition is usually restricted to the renal vessels, but has been seen in other medium-sized arteries. It has a predilection for younger patients, usually females, but this condition can occur at all ages and in either sex. Its origin is unknown, but, as is usual in such circumstances, infection, endocrine factors, and collagen diseases have been invoked in a causative role (Van Wyk, 1964). In fact the pathological findings most closely resemble the dysplastic conditions of the tunica media seen in Marfan's syndrome and in Erdheim's medio-necrosis, but these resemblances still leave the cause an unsolved problem.

From the practical viewpoint this condition should be treated in the same way as renal artery stenosis of other causes, and, as the above case illustrates, in carefully selected cases surgical treatment can be most rewarding.

\section{Summary}

A case of vertebrobasilar insufficiency due to hypertension and polycythaemia associated with fibromuscular hyperplasia of one renal artery is described. This is a rare cause of " renal " polycythaemia. The possible underlying mechanisms of this association are discussed, and it is suggested that renal ischaemia may increase erythropoietin activity.

We are indebted to Dr. D. N. S. Kerr for carrying out the differential renal-function tests, and to Dr. R. Brown and Mr. J. Haggith for the red-cell-mass studies. Dr. Brown also carried out the estimation of erythropoietin activity. We are also grateful to Dr. J. N. Walton for permission to publish the case report.

\section{REFERENCES}

Blanshard, G., and Smith, H. (1964). Brit. F. Urol.. 36, 66.
Brandt, P. W. T., Dacie, J. V., Steiner, R. E., and Szur, L. (1963). Brit. med. F., 2,468 .

Conley, C. L.. Kowal, J., and D'Antonio, J. (1957). Bull. Fohns Hopk. Hosp., 101, 63.

Damon, A., Holub, D. A., Melicow, M. M., and Uson, A. C. (1958) Amer. .. Med., 25, 182 . De Gruchy, G. C. (1964). Clinical Haematology, 2nd ed., chap. 11.

Gaisböck, F. (1905). Dtsch. Arch. klin. Med., 83, 363.

Gardner, F. H., and Freymann, J. G. (1958).' New Engl. 7. Med., 259,

Gurney, C. W., Wackman, N., and Filmanowicz, E. (1961). Blocd, 17,

Jacobson, L. O., Goldwasser, E., Fried, W., and Plzak, L. F. (1957). Trans. Ass. Amer. Phycns, 70, 305.

Jones, N. F., Payne, R. W., Hyde, R. D., and Price, T. M. L. (i960), Lancet, $1,299$.

Lawrence, J. H., and Donald, W. G., jun. (1959). Ann. intern. Med.,

50, 959.
Luke, R. G., Kennedy, A. C., Barr Stirling, W., and McDonald, G. A. (1965). Brit. med. F., 1, 164.

Naets, J.-P. (1963). In Hormones and the Kidney, edited by P. C. Williams, p. 175. Academic Press, London

Nathan, D. G., Schupak, E., and Merrill, J. P. (1963). Blood, 22, 811

Osnes, S. (1959). Brit. med. F., 2, 650

Penington, D. G. (1962). Postgrad. med. 7., 38, 497.

Smith, H., and Riches, E. (1963). Lancet, 1, 1017.

Van Dyke, D., Keighley, G., and Lawrence, J. (1963). Blood, 22, 838.

Van Wyk F. A. K. (1964). S. Afr. med. F., 38, 515. 